\title{
Factors Associated with Musculoskeletal Disorders among Registered Nurses: Evidence from the Thai Nurse Cohort Study \\ Thinkhamrop $\mathrm{W}^{1}{ }^{1}$ Laohasiriwong $\mathrm{W}^{2}$
}

${ }^{1}$ Program in Public Health, Faculty of Public Health

${ }^{2}$ Faculty of Public Health, Board Committee of Research and Training Centre for Enhancing Quality of Life of Working Age People (REQW)

Khon Kaen University, Khon Kaen 40002, Thailand.

\section{Corresponding Author}

Wongsa Laohasiriwong

Faculty of Public Health, Board Committee of Research and Training Centre for Enhancing Quality of Life of Working Age People (REQW),

Khon Kaen University, Khon Kaen 40002, Thailand

E-mail: drwongsa@gmail.com

Citation

Thinkhamrop W, Laohasiriwong W. Factors Associated with Musculoskeletal Disorders among Registered Nurses: Evidence from the Thai Nurse Cohort Study. Kathmandu Univ Med J 2015;51(3):238-43.

\section{ABSTRACT}

\section{Background}

Health, safety, and well being have been known to be influenced by occupational characteristics. Nurses constantly encounter musculoskeletal disorders (MSDs) from work demands worldwide. Nevertheless, there is insufficient of knowledge regarding causes of musculoskeletal disorders among nurses in Thailand.

\section{Objective}

To investigate factors associated with musculoskeletal disorder among registered nurses in Thailand.

\section{Method}

This study is part of the 2009 Thai Nurse Cohort Study which consisted of 18,756 nationally representative sample of registered nurses. Data collection was performed via postal self-administered questionnaires. Manifesting musculoskeletal disorders was self-reported by registered nurses, 1,070 nurses were excluded since they were unemployed during previous 12 months. Multiple logistic regression was used for data analysis.

\section{Result}

Of 17,686 registered nurses, the overall 12 months prevalence of musculoskeletal disorders was $47.8 \%$. It was found that workplace violence was the strongest factor which statistically significant associated with musculoskeletal disorders (adjusted odds ratio, $\mathrm{OR}, 2.01 ; 95 \%$ confidence interval, $95 \% \mathrm{Cl}, 1.42$ to 2.83 ; $\mathrm{P}<0.001$ ), anxiety/depression ( $\mathrm{OR}=1.96: 95 \% \mathrm{Cl}: 1.78$ to $2.15 ; \mathrm{P}<0.001$ ), perceiving job required a lot of physical effort ( $O R=1.69 ; 95 \% \mathrm{Cl}: 1.52$ to $1.87 ; \mathrm{P}<0.001)$, every 10 years increased of age $(\mathrm{OR}=1.40 ; 95 \% \mathrm{Cl}: 1.22$ to $1.62 ; \mathrm{P}<0.001)$, overweight $(\mathrm{OR}=$ 1.39; $95 \% \mathrm{Cl}: 1.01$ to $1.52 ; \mathrm{P}=0.015)$.

\section{Conclusion}

Registered nurses were most vulnerable of musculoskeletal disorders especially those who experienced workplace violence, anxiety/depression, strenuous work, older age, and overweight. Consequently, recommending safety practices to nurses should be considered for musculoskeletal disorders (MSDs) prevention by ergonomics and workplace design.

\section{KEY WORDS}

Cohort study, musculoskeletal disorders (MSDs), registered nurse. 


\section{INTRODUCTION}

Nursing profession globally has highest risk of musculoskeletal disorders (MSDs) due to their work demands and others inevitably performances at work such as patient or object handling,,$^{1,2}$ awkward postures, as well as individual, psychosocial and organization factors. ${ }^{3-7}$ In Eastern country, perceived physical demands were associated with MSDs (OR = 2.04 to 7.24). ${ }^{8}$ Studies in Western countries reported that highly demands at work increased MSDs (OR = 12.0). ${ }^{9}$ Experiencing workplace violence induced the risk of MSDs (prevalences ratio $=1.43$ and 2.7), ${ }^{10-13}$ workplace factors and health factors were also counted as related factors. ${ }^{14}$ In addition, perceiving strenuous workload associated with MSDs (OR = 1.93 to 3.51), ${ }^{15-17}$ as well as perceiving psychosocial issues (OR = 1.72), ${ }^{17}$ and being stress (OR $=2.4$ to 4.0$) .{ }^{18,19}$ In Asia, nurses who perceived the lack of staffing at work and worked at night affected on their back, ${ }^{20}$ and insufficient sleep was leading cause of arm and leg pain. ${ }^{21}$ Moreover, individual factors such as age, body mass index, and work experience were found that related to MSDs., ${ }^{8,15,22-24}$

In Thailand, a few studies demonstrated that MSDs related psychosocial factors, manual handling and lack of exercise..$^{25-27}$ However, these studies conducted in specific areas and did not focus on nurses only. Therefore, those findings cannot be generalized to all various nursing profession throughout Thailand.

This study, therefore investigates factors associated with MSDs among registered nurses (RNs) in Thailand based on a large, nationally representative sample of RNs.

\section{METHODS}

\section{Study design}

This study utilized data from database of the first wave of the Thai Nurse Cohort Study (TNCS), which is a 20 -year longitudinal cohort study conducted in 2009. Data collection took places biennially with the purpose of investigating the workforce dynamics and health conditions of RNs in Thailand. A nationwide representative sample was selected from Thai RNs who holding nursing licenses granted by the Thai Nursing and Midwifery Council as of 2008 using agestratified random sampling technique from 5 year-interval age-groups, from 20 to 64 years old i.e., < 25, 25-29, 3034, 35-39, 40-44, 45-49, 50-54, 55-59, and 60-64 years. The initial estimated sample size of the TNC was 50,200 RNs, therefore the average size of each stratum would be 5,578 . The seven age groups were then randomly selected proportional to size of each strata. Data collection by using self-administered questionnaires mailed through the post. Reliability of 0.81 was estimated by using Cronbach's alpha. Validity was arranged by the ten experts to obtain the finalized version of questionnaire. Two occasions of reminder were done by a phone call and e-mail after two months following the first delivery of the questionnaire and one month after that. The RNs who completed the questionnaires and signed with dated in the consent forms were enrolled as the TNCS cohort members.

\section{Dependent variable}

Dependent variable is musculoskeletal disorders (MSDs) defined as nurses reported experienced of having/had problems involving muscles, skeletons, and joints during the previous 12 months.

\section{Statistical Analysis}

For baseline characteristics, number and percentage were used to describe the categorical variables, the mean and standard deviation together with the range (Minimum: Maximum) were used to present the continuous variables. As the design of TNCS, probability sampling weight was used. For the study objective, simple logistic regression for survey sampling was analyzed to estimate the association between each potential related factor with MSDs and presented as unadjusted odds ratio and its $95 \%$ confidence interval $(95 \% \mathrm{Cl})$ of each parameter, multiple logistic regression was used to estimate the magnitude of association of factors and MSDs by adjusting the covariates, and reported as adjusted odds ratio together with its $95 \%$ $\mathrm{Cl}$. Statistically significant level of the study was assigned to less than 0.05 of $P$ value for all two-sided statistical tests. All analyses were performed using Stata version 13 (Stata Corp, College Station, TX).

\section{Ethical conduct of the study}

The Institutional Review Board of the Ministry of Public Health had approved the proposal of the TNCS. Obtaining the willingness from participants was done before enrolment. Confidentiality of participants' information was fully concerned. This study was approved by the Ethical Committee of Khon Kaen University.

\section{RESULTS}

\section{Response to questionnaire}

A total of 142,699 RNs were formed as the population of the study. A sample of 50,209 was randomly selected based on stratified random sampling technique with probability proportional to size of nurses in each 5-year age stratum, from 20 to 64 years old. The questionnaires were then delivered to them. Of these, 18,200 were excluded due to incorrect mail addresses, therefore the remainders of 32,009 received the questionnaires, 18,756 (58.60\%) responded. We excluded $1,070 \mathrm{RNs}$ since they were unemployed in the previous 12 months, therefore information of 17,686 active RNs were analyzed for the study (Figure 1).

\section{Baseline characteristics}

Of the $17,686 \mathrm{RNs}$, their mean age was 43.51 years old (S.D. $=9.63$ years old), most of them were $40-49$ years 


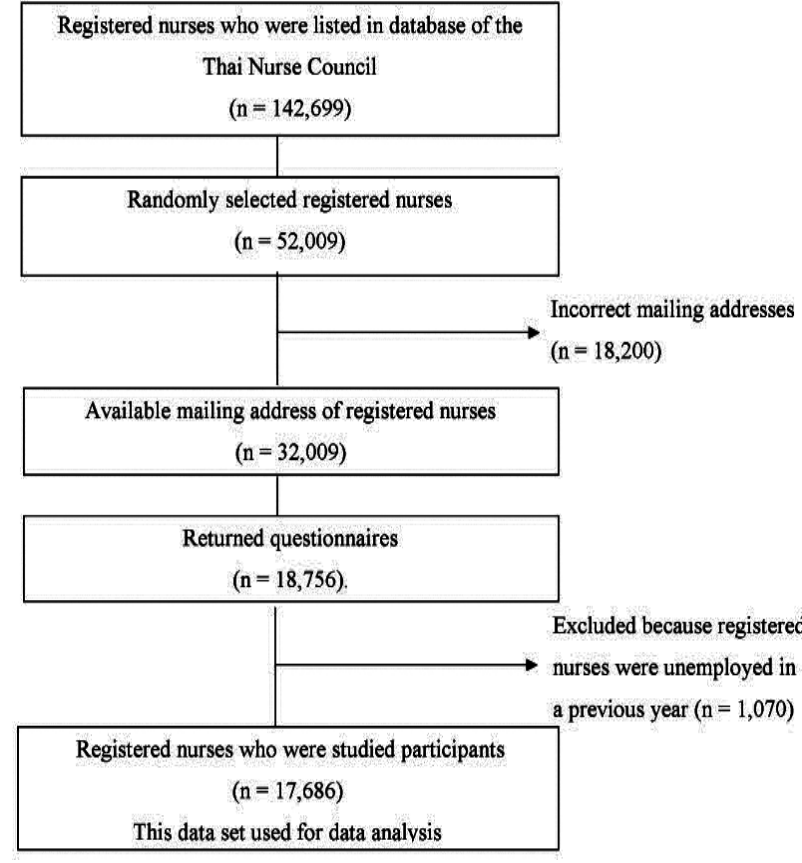

Figure 1. The inclusion flow chart

old (36.10\%), and almost all were female (97.33\%) (Table 1). Normal body mass index (BMI) was predominant appearance with its mean of $22.71 \mathrm{~kg} /$ height $^{2}\left(\mathrm{~m}^{2}\right)$ (SD $=3.51 \mathrm{~kg} / \mathrm{m}^{2}$ ). Most were working as a service nurse (74.48\%), about one third (36.25\%) has been working between 21 and 30 years. More than half perceived the job required a lot of physical effort and anxiety/depression (67.05\% and $60.06 \%$, respectively). Nearly all experienced workplace violence (WPV) (98.48\%).

\section{Table 1. Baseline characteristics of registered nurses}

\begin{tabular}{|llc|}
\hline Characteristics & $\begin{array}{l}\text { Number } \\
(\mathbf{n}=17,686)\end{array}$ & $\begin{array}{c}\text { Percent } \\
(\%)\end{array}$ \\
\hline Age (years) & 1,995 & 11.28 \\
\hline $20-29$ & 4,235 & 23.95 \\
\hline $30-39$ & 6,384 & 36.10 \\
\hline $40-49$ & 4,727 & 26.73 \\
\hline $50-59$ & 345 & 1.95 \\
\hline 60 or greater & $43.51 \pm 9.63$ & \\
\hline Mean \pm standard deviation & $20.5: 65.4$ & \\
\hline Range (Minimum : Maximum) & & \\
\hline Gender & 472 & 2.67 \\
\hline Male & 17,206 & 97.33 \\
\hline Female & & \\
\hline Body Mass Index (kg/m ${ }^{2}$ ) & 730 & 4.19 \\
\hline Lower than 18 & 13,030 \\
\hline $18-24.99$ & 3,660 & 74.80 \\
\hline 25 or greater & $22.71 \pm 3.51$ \\
\hline Mean \pm standard deviation & $13.9: 43.8$ \\
\hline Range (Minimum : Maximum) & & \\
\hline Employment category & 13,172 & 74.48 \\
\hline Service nurses & & \\
\hline
\end{tabular}

\begin{tabular}{|c|c|c|}
\hline Research nurses & 1,187 & 6.71 \\
\hline Administrative nurses & 3,327 & 18.81 \\
\hline \multicolumn{3}{|l|}{ Duration of working (years) } \\
\hline 10 or smaller & 2,564 & 14.51 \\
\hline $11-20$ & 4,770 & 26.99 \\
\hline 21-30 & 6,406 & 36.25 \\
\hline 31 or greater & 3,934 & 22.26 \\
\hline Mean \pm standard deviation & $21.5 \pm 9.9$ & \\
\hline Range (Minimum : Maximum) & $0.08: 45.0$ & \\
\hline \multicolumn{3}{|l|}{ Shift work } \\
\hline Non shift & 3,573 & 20.56 \\
\hline Shift & 13,804 & 79.44 \\
\hline \multicolumn{3}{|c|}{ Night time workload (at least 4 days monthly) } \\
\hline No & 8,007 & 45.92 \\
\hline Yes & 9,431 & 54.08 \\
\hline \multicolumn{3}{|l|}{ Working hour (previous a month) } \\
\hline More than 12 hours at least a day & 7,771 & 44.76 \\
\hline Regular time & 8,212 & 47.30 \\
\hline Unemployed & 1,377 & 7.93 \\
\hline \multicolumn{3}{|l|}{ Sleeping hour } \\
\hline Less than 7 & 8,913 & 53.01 \\
\hline $7-9$ & 7,572 & 45.04 \\
\hline More than 9 & 328 & 1.95 \\
\hline Mean \pm standard deviation & $6.60 \pm 1.25$ & \\
\hline Range (Minimum : Maximum) & $6(2: 20)$ & \\
\hline \multicolumn{3}{|c|}{ Perceiving job required a lot of physical effort } \\
\hline No & 11,699 & 67.05 \\
\hline Yes & 5,748 & 32.95 \\
\hline \multicolumn{3}{|l|}{ Workplace Violence } \\
\hline No & 16,551 & 98.48 \\
\hline Yes & 256 & 1.52 \\
\hline \multicolumn{3}{|l|}{ Anxiety/Depression } \\
\hline No & 10,551 & 60.06 \\
\hline Yes & 7,016 & 39.94 \\
\hline
\end{tabular}

\section{Factors associated with MSDs: bivariate analysis}

Among 17,686 RNs, the overall 12 months prevalence of MSDs was $47.8 \%$ (Table 2). There were statistically significant association between each factor and MSDs. Without adjusting for covariates, it was found that nurses who had BMI $25 \mathrm{~kg} / \mathrm{m}^{2}$ or greater were 1.31 times higher risk of developing MSDs than those who had BMI lower than $18 \mathrm{~kg} / \mathrm{m}^{2}$ (95\% Cl; 1.09 to 1.57$)$. Service nurses were more likely to develop MSDs than other types of nurses, research nurse and administrative nurse $(O R=1.20 ; 95 \% \mathrm{Cl}$ : 1.04 to $1.41 ; \mathrm{OR}=1.04 ; 95 \% \mathrm{Cl}: 1.12$ to 1.16 , respectively). Moreover, working at night time $(\mathrm{OR}=1.39 ; 95 \% \mathrm{Cl}: 1.29$ to 1.50). RNs with anxiety/depression were 2.08 times more likely to develop MSDs compared to those who did not have the problems ( $95 \% \mathrm{Cl}: 1.93$ to 2.24 ), and experiencing WPV was 2.56 times most likely to develop MSDs compared to the RNs who without WPV (95\% Cl: 1.90 to 3.46$)$. 
Table 2. Factors influencing musculoskeletal disorders considering each factor based on simple logistic regression analysis: bivariate analysis

\begin{tabular}{|c|c|c|c|c|c|}
\hline Factors & No. & \%MSD & $\begin{array}{c}\text { Unadjusted } \\
\text { OR }\end{array}$ & $95 \% \mathrm{Cl}$ & $P$ value \\
\hline $\begin{array}{l}\text { Age (every } 10 \\
\text { years) }\end{array}$ & 17,686 & 47.8 & 1.70 & $1.15-2.28$ & $<0.001$ \\
\hline Gender & & & & & 0.130 \\
\hline Male & 456 & 42.1 & 1.00 & & \\
\hline Female & 16,850 & 47.9 & 1.19 & $0.95-1.50$ & \\
\hline \multicolumn{5}{|c|}{ Body Mass Index $\left(\mathrm{kg} / \mathrm{m}^{2}\right)$} & 0.002 \\
\hline Lower than 18 & 715 & 44.1 & 1.00 & & \\
\hline $18-24.99$ & 12,778 & 46.7 & 1.11 & $0.94-1.31$ & \\
\hline 25 or greater & 3,576 & 52.6 & 1.31 & $1.09-1.57$ & \\
\hline \multicolumn{5}{|c|}{ Employment category } & 0.026 \\
\hline Service nurses & 12,901 & 48.0 & 1.00 & & \\
\hline Research nurses & 1,159 & 45.3 & 0.83 & $0.71-0.96$ & \\
\hline $\begin{array}{l}\text { Administrative } \\
\text { nurses }\end{array}$ & 3,250 & 47.6 & 0.89 & $0.86-1.07$ & \\
\hline \multicolumn{5}{|c|}{ Duration of working (years) } & $<0.001$ \\
\hline 10 or smaller & 2,520 & 44.8 & 1.00 & & \\
\hline $11-20$ & 4,684 & 44.8 & 0.97 & $0.87-1.07$ & \\
\hline $21-30$ & 6,287 & 49.5 & 1.16 & $1.07-1.29$ & \\
\hline 31 or greater & 3,808 & 50.6 & 1.23 & $1.11-1.37$ & \\
\hline Shift work & & & & & $<0.001$ \\
\hline Non shift & 3,573 & 44.2 & 1.00 & & \\
\hline Shift & 13,804 & 48.6 & 1.19 & $1.11-1.29$ & \\
\hline \multicolumn{5}{|c|}{ Night time work (at least 4 days monthly) } & $<0.001$ \\
\hline No & 7,843 & 44.3 & 1.00 & & \\
\hline Yes & 9,237 & 50.8 & 1.39 & $1.29-1.50$ & \\
\hline \multicolumn{5}{|c|}{ Working hour (previous a month) } & $<0.001$ \\
\hline Unemployed & 1,320 & 42.4 & 1.00 & & \\
\hline $\begin{array}{l}\text { More than } 12 \\
\text { hours per day }\end{array}$ & 7,638 & 51.1 & 1.48 & $1.27-1.71$ & \\
\hline Regular time & 8,051 & 45.5 & 1.12 & $0.97-1.30$ & \\
\hline Sleeping hour & & & & & $<0.001$ \\
\hline More than 9 & 318 & 35.22 & 1.00 & & \\
\hline Less than 7 & 8,727 & 52.34 & 1.95 & $1.59-2.55$ & \\
\hline $7-9$ & 7,433 & 43.32 & 1.38 & $1.11-1.78$ & \\
\hline \multicolumn{5}{|c|}{ Anxiety/Depression } & $<0.001$ \\
\hline No & 10,317 & 40.5 & 1.00 & & \\
\hline Yes & 6,888 & 58.6 & 2.08 & $1.93-2.24$ & \\
\hline \multicolumn{5}{|c|}{ Perceiving job required a lot of physical effort } & $<0.001$ \\
\hline No & 11,471 & 43.7 & 1.00 & & \\
\hline Yes & 5,634 & 56.1 & 1.73 & $1.61-1.87$ & \\
\hline \multicolumn{5}{|c|}{ Workplace Violence } & $<0.001$ \\
\hline No & 16,248 & 47.6 & 1.00 & & \\
\hline Yes & 255 & 67.1 & 2.56 & $1.90-3.46$ & \\
\hline
\end{tabular}

$95 \% \mathrm{Cl}=95 \%$ confidence interval; MSD = musculoskeletal disorders; Unadjusted $\mathrm{OR}=$ Odds ratio obtained from using simple logistic regression

\section{Factors associated with MSDs: multivariable analysis}

Experiencing workplace violence had the strongest influence on MSDs among RNs when compared to those with no WPV (adjusted odds ratio, OR $=2.01 ; 95 \% \mathrm{Cl}: 1.42$ to 2.83; $\mathrm{P}<0.001$ ), perceiving anxiety/depression (OR = 1.96; $95 \% \mathrm{Cl}: 1.78$ to $2.15 ; \mathrm{P}<0.001$ ), perceiving job required a lot of physical effort at work (OR $=1.69 ; 95 \%$ $\mathrm{Cl}: 1.52$ to $1.87 ; \mathrm{P}<0.001$ ) (Figure 2). For every 10 years increased of age, the risk for MSDs increased 1.40 times $(\mathrm{OR}=1.40 ; 95 \% \mathrm{Cl}: 1.22$ to $1.62 ; \mathrm{P}<0.001)$, overweight $\left(\mathrm{BMI}>25 \mathrm{~kg} / \mathrm{m}^{2}\right)(\mathrm{OR}=1.39 ; 95 \% \mathrm{Cl}: 1.01$ to $1.53 ; \mathrm{P}=$ $0.015)$. Nurses who worked more than 12 hours per day (at least one day per month) were 1.36 times more likely to have MSDs compared to those who did not work $(95 \% \mathrm{Cl}$ : 1.11 to 1.66 : $P<0.001)$.

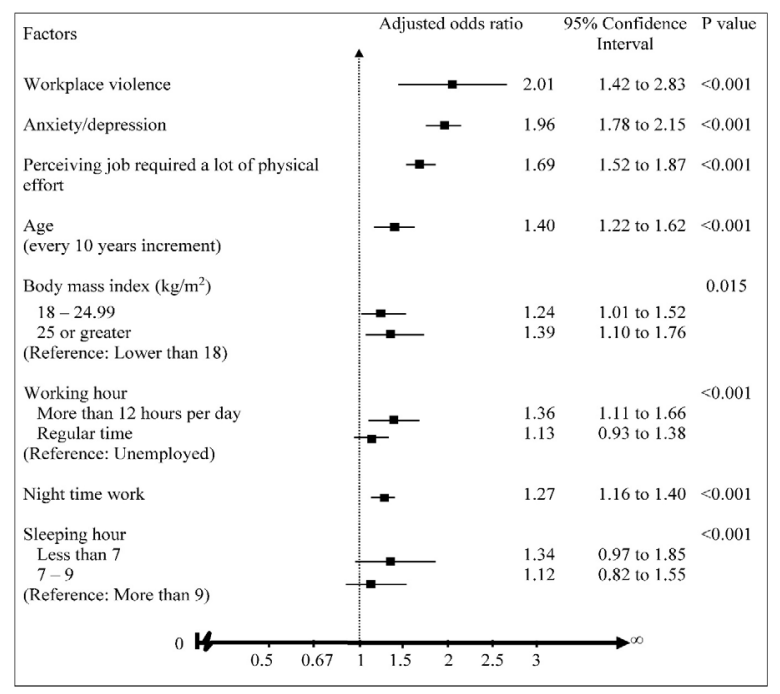

Figure 2. Factors influencing musculoskeletal disorders adjusting for covariates based on multiple logistic regression analysis: multivariate analysis

The above magnitude of association of significant factors was adjusted for the effect of gender, shift work, income, employment category of RNs, type of hospital, duration of working, having child/children, having part time job, continuously sitting hours per day, insufficient support from the chief of organization, lack of peer support, perceived being requested for too much work, and perceiving of not enough time to get job done (data were not shown in the paper).

\section{DISCUSSION}

This study documented the factors associated with MSDs among Thai RNs. The overall 12 months prevalence of MSDs was $47.8 \%$ in Thai RNs. For the associated factors, we found that WPV was the strongest factor contributed MSDs ( $\mathrm{OR}=2.01 ; 95 \% \mathrm{Cl}: 1.42$ to 2.83 ), which is similar with study in U.S., $2011-2014 .{ }^{10-13}$ These ratios were higher than that 
found in a study among health personnel in two hospitals in U.S., which reported prevalences ratio, PR, of non-physical WPV 1.43 (95\% Cl: 1.11 to 1.82). This high association might be due to the different definition of having WPV and of MSDs. We defined having WPV as at least one time of occurrence of any physical or non-physical WPV during a previous year among nurses, and having MSDs was defined as nurses reported experienced of having/had problems involving muscles, skeletons, and joints during the previous 12 months. In addition, the potential confounders which were adjusted for multivariate analysis were different in term of attributes and contexts. However, we found that the prevalence rates ratio was lower than another study in U.S. ( $P R=2.7 ; 95 \% \mathrm{Cl}: 1.8$ to 3.9). This might be due to the violent behaviors can be the actions of patients, clients, family members and public, of which often being accepted as part of the normal work environment in health care settings.

In addition, we found that RNs who perceived anxiety/ depression were 1.96 times more likely to develop MSDs compared to those who did not. This finding was related to the previous study in Canada, 2013. ${ }^{14}$ The association could be explained as nurses who perceived the anxiety/ depression are more likely to suffer from muscle tension and stress adjustment which are the most common cause of MSDs. Tension and stress lead to strain of muscles and harden them. In addition, nurses who had anxiety are prone to noticing all type of pain occurred with their body due to attended on negative feelings when they self-reported about their MSDs. Moreover, we found that every 10 years increased of age among RNs, MSDs were more likely to develop. It can explained in aspect of gender phenomenon that almost all nurse were female who were more likely to reflect and less likely to tolerate their unfavourable symptoms, particular among elders. ${ }^{8}$ We also found that overweight of BMI had slightly influenced on MSDs. It could be the contribution of pressure of extra weight to the spine while performing awkward postures inevitably. It is one of discomfort on muscle which increased the pain. These associations were consistent with various studies. ${ }^{8,22}$

The assigned night work was usually between 7 p.m. and 7 a.m. The impact of working at night on MSDs that we found might be the common complaint on leg(s) so-called "night time leg cramps" which are usually sudden spasms, or tightening, of muscles in the calf. The muscle cramps often occur just in the night time accompanied by overnight job. It might relate to insufficient sleep that is well recognized as a contributing factor on stress among nurses. ${ }^{21}$

We found that nurses who continuously worked for more than 12 hours per day, considered as an extra- time, (at least one day per month) was more likely to have MSDs, 1.36 times, when compared with those who worked regular time. Long work hours might relate with reducing the time available for sleep, leading to sleep deprivation or disturbed sleep and incomplete recovery from work. ${ }^{21}$ It might also relate with awkward posture while performing their duties. Our study finding confirmed that lack of sleep among nurses was statistically significant associated with MSDs, the nurses who slept less than 7 hours per day had higher risk of MSDs when compared with those who slept more than 9 hours daily. Furthermore, we found that nurses who perceived that their job required a lot of physical effort were more likely to have MSDs compared to those who did not. The feelings about working climate among nurses were also related with strain, of which is one of a common factor contributed to MSDs, similar with the study in $2010 .^{16}$

There were some limitations in this study. Firstly, this study was part of the TNCS. As a result the instrument was developed for several research purposes, not focus only on the aspect of musculoskeletal disorders, some information are not available. Secondly, despite the strength of selfadministered questionnaire is increasing accuracy of information since the respondent will not worry of their confidentiality asking information of the past 12 months, recalled bias and underreport may skew the results. In this case, the context and comparison with other study have help reduced the possible information bias, since this study use the first wave of the TNCS, it is considered a crosssectional study design, therefore, we could not indicate the real cause of MSDs, just the associated factors.

\section{CONCLUSION}

Musculoskeletal disorders (MSDs) affected almost half of RNs in Thailand annually. Our study confirms that Thai RNs were the most vulnerable for MSDs. The contributing factors included workplace violence, anxiety/depression, perceiving job required a lot of physical effort at work, elder, high BMI, and night time work. Most of these influencing factors were relevant to workplace designs, individual factors, and ergonomic factors, which could resulted in various types of MSDs. Consequently, recommending safety practices to nurses should be considered for MSDs prevention by ergonomics and workplace design.

\section{ACKNOWLEDGEMENTS}

The authors appreciate the contributions of all members of the Thai Nurse Cohort Study for their valuable supports. We recognize that the Cohort contributes to better understanding on the "life and work" of registered nurses in Thailand and an evidence based policy formulation. 


\section{REFERENCES}

1. Stubbs B. The manual handling of the aggressive patient: a review of the risk of injury to nurses. J Psychiatr Ment Health Nurs 2009 May;16(4):395-400.

2. Waters T, Spera P, Petersen C, Nelson A, Hernandez E, Applegarth S. AORN Ergonomic Tool 3: lifting and holding the patient's legs, arms, and head while prepping. AORN J 2011 May;93(5):589-92.

3. Nia. HS, Chan. YH, Kalantari. S, Afshar. MH, Taghipour. B, Kaveh. H, et al. Evaluation of Ergonomic Factors Associated with Musculoskeletal Disorders in Nurses. AENSI Journals 2014;8(6):3125-9.

4. Rogers B, Buckheit K, Ostendorf J. Ergonomics and nursing in hospital environments. Workplace Health Saf 2013 Oct;61(10):429-39.

5. Lee SJ, Faucett J, Gillen M, Krause N, Landry L. Factors associated with safe patient handling behaviors among critical care nurses. Am J Ind Med 2010 Sep;53(9):886-97.

6. Geiger-Brown J, Lipscomb J. The health care work environment and adverse health and safety consequences for nurses. Annu Rev Nurs Res 2010;28:191-231.

7. Gershon RR, Stone PW, Zeltser M, Faucett J, MacDavitt K, Chou SS. Organizational climate and nurse health outcomes in the United States: a systematic review. Ind Health 2007 Oct;45(5):622-36.

8. Choobineh A, Movahed M, Tabatabaie SH, Kumashiro M. Perceived demands and musculoskeletal disorders in operating room nurses of Shiraz city hospitals. Ind Health 2010;48(1):74-84

9. Trinkoff AM, Lipscomb JA, Geiger-Brown J, Storr CL, Brady BA. Perceived physical demands and reported musculoskeletal problems in registered nurses. Am J Prev Med 2003 Apr;24(3):270-5.

10. Sabbath EL, Hurtado DA, Okechukwu CA, Tamers SL, Nelson C, Kim SS, et al. Occupational injury among hospital patient-care workers: what is the association with workplace verbal abuse? Am J Ind Med 2014 Feb;57(2):222-32.

11. Yang LQ, Spector $\mathrm{PE}$, Chang $\mathrm{CH}$, Gallant-Roman $\mathrm{M}$, Powell J. Psychosocial precursors and physical consequences of workplace violence towards nurses: a longitudinal examination with naturally occurring groups in hospital settings. Int J Nurs Stud 2012 Sep;49(9):1091-102.

12. Miranda H, Punnett L, Gore R, Boyer J. Violence at the workplace increases the risk of musculoskeletal pain among nursing home workers. Occup Environ Med 2011 Jan;68(1):52-7.

13. Hess R, Desroches C, Donelan K, Norman L, Buerhaus PI. Perceptions of nurses in magnet(R) hospitals, non-magnet hospitals, and hospitals pursuing magnet status. J Nurs Adm 2011 Jul-Aug;41(7-8):315-23.

14. Murray E, Franche RL, Ibrahim S, Smith $P$, Carnide $N$, Cote $P$, et al. Pain-related work interference is a key factor in a worker/workplace model of work absence duration due to musculoskeletal conditions in Canadian nurses. J Occup Rehabil 2013 Dec;23(4):585-96.
15. Chao-Kang Feng, Mei-Lien Chen a, Mao I-F. Prevalence of and risk factors for different measures of low back pain among female nursing aides in Taiwanese nursing homes. BMC Musculoskelet Disord 2007;8(52).

16. Fonseca NR, Fernandes RCP. Factors Related to Musculoskeletal Disorders in Nursing Workers. Rev. Latino-Am. Enfermagem 2010;18(6):1076-83.

17. Pekkarinen L, Elovainio M, Sinervo T, Heponiemi, Tarja; Aalto, Anna-Mari; , et al. Job demands and musculoskeletal symptoms among female geriatric nurses: The moderating role of psychosocial resources. J Occup Health Psychol 2013;18(2):211-9.

18. Mehrdad R, Dennerlein JT, Haghighat M, Aminian O. Association between psychosocial factors and musculoskeletal symptoms among Iranian nurses. Am J Ind Med 2010 Oct;53(10):1032-9.

19. Warming S, Precht DH, Suadicani P, Ebbehoj NE. Musculoskeletal complaints among nurses related to patient handling tasks and psychosocial factors--based on logbook registrations. Appl Ergon $2009 \mathrm{Jul} ; 40(4): 569-76$.

20. Cho KJJaS-H. Low back pain and work-related factors among nurses in intensive care units. Clinical Nursing 2009;20:479.

21. Takahashi M, Iwakiri K, Sotoyama M, Hirata M, Hisanaga N Musculoskeletal pain and night-shift naps in nursing home care workers. Occup Med (Lond) 2009 May;59(3):197-200.

22. Reed LF, Battistutta D, Young J, Newman B. Prevalence and risk factors for foot and ankle musculoskeletal disorders experienced by nurses. BMC Musculoskelet Disord 2014;15:196.

23. Schoenfisch AL, Lipscomb HJ. Job characteristics and work organization factors associated with patient-handling injury among nursing personnel. Work 2009;33(1):117-28

24. Tinubu BM, Mbada CE, Oyeyemi AL, Fabunmi AA. Work-related musculoskeletal disorders among nurses in Ibadan, South-west Nigeria: a cross-sectional survey. BMC Musculoskelet Disord 2010;11:12.

25. Jin; S, Srisaenpang; S, Pinitsoontorn; S, Eungpinichpong W. Prevalence of work-related musculoskeletal diorders among registered nurese in Srinagarind hospital, Thailand. J Health Res 2011;25(2):61-8.

26. Silpasupagornwongse S, Kumthornthip W, Assawapalangchai S, P P. The Study of Prevalence, Risk Factors and Impact of Low Back Pain among Nurses and Nurse-aids in Siriraj Hospital. J Thai Rehabil 2006;16(3):128.

27. Sopajareeya C, Viwatwongkasem C, Lapvongwatana P, Hong O, S K. Prevalence and Risk Factors of Low Back Pain among Nurses in a Thai Public Hospital. J Med Assoc Thai 2009;92(7):93-9. 